Orehek, E., Forest, A. L., \& Wingrove, S. (2018). People as Means to Multiple Goals: Implications for Interpersonal Relationships. Personality and Social Psychology Bulletin, 44, 1487-1501.

Final published version available here:

http://journals.sagepub.com/doi/full/10.1177/0146167218769869

People as Means to Multiple Goals: Implications for Interpersonal Relationships

Edward Orehek

Amanda L. Forest

University of Pittsburgh

Sara Wingrove

Duke University 


\begin{abstract}
The present research examines the implications of having relationship partners who serve as means to multiple goals. Specifically, we test the hypotheses that (1) partners who serve more goals will be evaluated as more interpersonally close, supportive, and responsive than those who serve fewer goals, and (2) partners who serve more goals will be less common in social networks than those who serve fewer goals. Three studies $(\mathrm{N}=1064)$ found consistent support for these hypotheses while examining relationships with all members of participants' active social network and their full range of goal pursuits. In addition, we found that the association between number of goals a partner serves and relationship evaluation is stronger for people who perceived their social networks as less (vs more) instrumental on average, and among people who perceived their relationships as less close, less supportive and less responsive, on average. Implications for close relationships are discussed.
\end{abstract}

Keywords: people-as-means; interpersonal closeness; social support; partner responsiveness; goal pursuit; multifinality 


\section{People as Means to Multiple Goals: Implications for Close Relationships}

Goal pursuit and close relationships are intimately intertwined in a way that makes it difficult to depict one without the other. A recent theoretical perspective outlined the way in which the link between close relationships and goal pursuit can be understood by considering people as means to goals (Orehek, 2018; Orehek \& Forest, 2016; Orehek, Forest, \& Barbaro, in press). For example, the goal to have fun on Friday evening is aided by many means, including delicious food, a strong cocktail, groovy tunes, and of course the other people who join in the merriment. When a person pursues a goal, the means that serve the goal —in this case, the food, the drinks, the music — are evaluated more positively than when the person does not have that goal in mind (Ferguson, 2008; Ferguson \& Bargh, 2004; Fishbach, Shah, \& Kruglanski, 2004; Fitzsimons \& Shah, 2008). A people-as-means approach points out that, just as objects and activities are evaluated according to their usefulness to a person's goals, so too are their relationship partners.

Research has demonstrated that people feel interpersonally closer to (Fitzimons \& Fishbach, 2010; Fitzsimons \& Shah, 2008), feel more gratitude for (Converse \& Fishbach, 2012), and want to spend more time with (Slotter \& Gardner, 2011) instrumental (vs. non-instrumental) partners. These findings have made a substantial impact on motivation and relationship science. They spurred several theoretical advances, including a new understanding of transactive goal dynamics (Fitzsimons, Finkel, \& vanDellen, 2015), objectification (Orehek \& Weaverling, 2017), close relationships (Finkel, Hui, Carswell, \& Larson, 2014; Finkel \& Eastwick, 2015; Light \& Fitzsimons, 2014; Orehek, 2018; Orehek \& Forest, 2016; Orehek et al., in press), and cooperative goal pursuit (Fishbach, Steinmetz, \& Tu, 2016; Fishbach \& Tu, 2016).

Although the foregoing research supports the notion that people evaluate others 
according to their perceived instrumentality to a single goal, people have many goals (Kruglanski et al., 2002; Neal et al., 2017; Orehek \& Vazeou-Nieuwenhuis, 2013; Vancouver et al., 2010), and are embedded in social networks in which they have multiple partners who could serve as means to those goals (Armstrong \& Kammrath, 2015; vanDellen, Shah, \& Leander, 2015). The present research examines the links between partner instrumentality and relationship evaluations in a paradigm that considers how all members of a person's active social network serve the full range of their goal pursuits. We investigate the influence of having a partner who serves many (as compared to fewer) goals on relationship evaluation.

Research has shown that non-social means attached to multiple goals are evaluated more positively than are non-social means to single goals (Chun et al., 2011; Orehek et al., 2012). Based on the multifinality principle (Kruglanski et al., 2002; Kruglanski et al., 2013)—which states that a means accrues greater value when it serves more goals - we predicted that relationship partners who serve more (versus fewer) goals should be evaluated more positively. While understanding how partners serve as means to multiple goals is both theoretically and practically important, no research has investigated this question. The present research was designed to fill this gap.

Although people prefer multifinal others, we expect such individuals to be relatively rare in social networks. The multifinality constraints effect states that there are fewer means that serve a large set of goals than there are means that serve a smaller set of goals (Köpetz et al., 2011). For example, finding tasty food may be easy, but finding tasty, convenient, healthy, and inexpensive food can be difficult (Orehek \& Vazeou-Nieuwenhuis, 2016). But does the multifinality constraints effect apply to instances in which people are means to goals? Finding a partner with whom you enjoy watching movies should be easier than finding a partner for whom 
you enjoy watching movies, cooking, raising children, having sex, and decorating a living room.

We test this possibility by asking participants to provide information about the instrumentality of all of their active social network members across a variety of goals, and assess the relative rarity or abundance of partners who serve an increasing number of goals.

\section{The Present Research}

The present research investigates the applicability of the multifinality principle to cases in which people serve as means to goals, and investigates this principle across a person's active social network. This allows us to capitalize on the richness of people's social networks and the simultaneous goals that any one individual is pursuing. We predict that partners who are instrumental to more goals will be evaluated more positively than partners who are instrumental to fewer goals. We also predict that partners who serve more goals will be less common in people's social networks than partners who serve fewer goals. Thus, the present work extends research on instrumentality by considering the interpersonal implications of cases in which people serve multiple goals. We also extend previous research by investigating a larger set of partners from a person's social network. We set out to understand whether the effects previously observed with a single instrumental (versus non-instrumental) partner extend throughout one's active social network.

Our study design allows us to test two important additional determinants of the link between the number of goals served by a partner and relationship evaluations. First, we investigated whether accounting for the importance of the goals served by the partner plays a role in relationship evaluations. Second, we explored whether social network instrumentalitythat is, a person's average perceived instrumentality across partners - moderates the strength of the association between perceptions of a particular partner's instrumentality and participants' 
evaluations of that particular partner. In other words, does the degree to which people link partner instrumentality to relationship evaluations vary as a function of how instrumental their social network is, as a whole? We reasoned that people whose social network overall is less instrumental may be especially sensitive to an individual partner's instrumentality because they have a greater need for an instrumental partner.

Investigation of our main hypotheses and these additional questions promises to have important implications for theories of goal pursuit and close relationships. This marks the first attempt to empirically investigate the applicability of the multifinality principle to instances in which people serve as means to goals. Because this principle is a fundamental aspect of goal systems theory, and goal systems theory does not distinguish between non-social and social means, this marks an important test for the generalizability of the theory. In addition, theorists interested in relationship evaluation have engaged in extensive speculation regarding the role of partner multifinality (Finkel et al., 2014; Finkel \& Eastwick, 2015; Light \& Fitzsimons, 2014; Orehek \& Forest, 2016; Orehek et al., in press), but have thus far had to do so without empirical evidence testing their claims.

\section{Study 1: Perceived Partner Instrumentality to Self-Generated Goals}

The aim of our first study was to provide an initial test of our predictions. Toward this aim, participants self-generated a list of all the goals served by each of their active social network members. Participants evaluated each relationship partner on dimensions of interpersonal closeness, perceived social support, and conversation quality. We predicted that the relative number of goals served by a partner would be positively associated with relationship evaluations. Although this prediction involves within-person variables (i.e., examining the association between person mean-centered partner instrumentality and reports of relationship 
outcomes for that partner), we followed the recommendations of Bolger and Laurenceau (2013), and included between-person averages in our models (i.e., each participant's average perceived partner instrumentality aggregated across all partners, grand mean-centered). We call this resulting participant-level variable "perceived network instrumentality" because it reflects the overall instrumentality of a participant's social network. Including this between-person predictor in our models accounts for potential confounding of the between-person and within-person levels of analysis. It also enables us to (a) examine whether participants who perceive their network members as more versus less instrumental, on average, also tend to report higher level of relationship outcomes, on average, and (b) create a cross-level interaction term (see Hoffman, 2014). This cross-level interaction term allowed us to explore whether the link between number of goals served by a particular partner and relationship evaluations of that partner was moderated by the participant's perceived network instrumentality (i.e., average level of perceived instrumentality across partners).

In addition, we expected that fewer social network members (i.e., partners) would be listed who serve increasing number of goals (i.e., partners who serve one goal would be more common than partners who serve three goals, who would be more common than partners who serve five goals). If this expectation was borne out, this would support the multifinality constraints hypothesis.

\section{Method}

\section{Participants}

Our recruitment target of 300 participants was determined based on the largest sample we expected that we could reasonably recruit in a single semester. In total, 298 undergraduates (162 male, 136 female) from an American university participated in this study. Three participants did 
not complete the survey, resulting in a final sample size of 295 participants. Each student received credit toward his or her introductory psychology course.

In each study, we sought to maximize power by aiming to run as many participants as we expected we could recruit within an academic semester, and to obtain information about multiple partners from each participant. Thus, our effective sample size at Level 1 (the level of the partner) is larger than the number of participants. In Study 1, across the three relationship evaluation measures, the smallest effective sample size calculated was 1024 . This sample size provided power of .95 to detect a small effect $\left(f^{2}=.013\right)$, two-tailed, in a model with one predictor (in our case, partner instrumentality).

\section{Materials and Procedure}

Participants completed all materials in our laboratory using paper and pencil questionnaires. After arriving at the laboratory, participants first completed individual difference measures not considered in the present investigation. Next, participants identified members of their social network (i.e., partners) by listing the first name of all individuals with whom they had initiated contact in the past month. Next, they listed all the goals for which each partner was instrumental. Participants then completed measures of interpersonal closeness, conversation quality, and perceived social support for each partner. Questionnaires were completed in the order in which they are listed.

Social Network Identification. Participants were asked to list all the people with whom they had initiated contact in the past month with allotted spaces for up to 20 people, following the recall procedure used by Dunbar and Spoors (1995). When making their lists, participants were asked to exclude casual acquaintances, coworkers seen only in a work capacity, and contact with professionals (e.g., their dentist). 
Perceived Partner Instrumentality for Self-Generated Goals. Participants were asked to complete a questionnaire about their relationship with each partner. Participants were asked to list any goals for which each partner was instrumental. There were no bounds on the number or type of goals that could be listed in this section, so participants were free to list as few or as many goals as they deemed appropriate. Participants were provided with the following explanation, adapted from Fitzsimons and Shah (2008, p. 324):

A person is instrumental to a goal if s/he makes it more likely that you will succeed. So, for example, an "instrumental person" might be emotionally supportive or help you directly with that goal. Note that being "non-instrumental" for your goals doesn't mean that this person wants you to fail - simply that he or she doesn't make it likelier that you will succeed.

Maps of social networks and goal systems were created using the software program Organization Risk Analyzer (ORA; Carley \& Reminga, 2004), a meta-network assessment and analysis tool. Goals and social network members were both inputted as nodes in a comma delineated value file with connections between nodes indicated in binary. This allowed us to visualize each participant's individual goal system, with people as means connected to their identified goals. Using ORA, we were able to identify the total number of goals, the number of partners serving each goal, and the number of goals served by each partner.

Interpersonal Closeness. Participants completed an interpersonal closeness inventory about each partner they had listed, including measures of perceived closeness and the Inclusion of Other in the Self Scale (IOS) (Aron, Aron, \& Smollan, 1992). Participants responded to the question of "How close do you feel to your friend right now?" on a 7-point Likert scale (1= not close at all, $7=$ extremely close), circled which pair of seven increasingly overlapping circles 
best described their relationship with their friend, and responded to the question of "How similar is your friend to you?" on a 7 -point Likert scale $(1=$ not similar at all, $7=$ extremely similar $)$. These items were averaged to create a composite score (as in Fitzsimons \& Shah, 2008). Across social network members, Cronbach's alpha ranged from .75 to .90 .

Conversation Quality. Participants completed a version of the Ordinary Conversation Scale (Lakey, Vander Molen, Fles, \& Andrews, 2016), which measured the perceived quality of conversations with each partner. Participants rated how much they agreed or disagreed with a series of eight statements describing their interactions with each partner on 5-point Likert scale ( 1 = strongly disagree, 5 = strongly agree). Example items include, "We have interesting conversations that last a long time," and "I forget our conversations soon after they are done." Across social network members, Cronbach's alpha ranged from .82 to .90 .

Perceived Social Support. Participants completed a version of the Quality of Relationships Inventory (Pierce, Sarason, \& Sarason, 1991) for each partner. Participants answered seven questions in which they rated the partner on the extent to which they could be expected to be supportive on a 4-point Likert scale ( $1=$ not at all, $4=$ very much). Examples of questions from the scale are, "To what extent can you count on him/her to listen to you when you are very angry at someone else?" and, "To what extent can you count on him/her to help you if a family member very close to you died?" Across interaction partners, Cronbach's alpha ranged from .72 to .88 .

\section{Results and Discussion}

\section{Descriptive Statistics}

As shown in Table 1, in this sample the average participant reported about nine partners, nine goals, with the average partner serving two goals. The average goal was served by two 
partners, and participants reported having about one non-instrumental partner per network—that is, one partner who served no goals. This resulted in a total of 2615 partners identified as means across the 295 participants. Among the social network members, 86 percent were instrumental to at least one goal (with 57 percent of participants reporting only instrumental others). Thus, participants identified most partners in their social network as facilitating their goal pursuit. Total number of goals generated by each participant was positively correlated social network size $(r(293)=.44, p<.001)$. This suggests that having more partners may allow a person to pursue more goals (perhaps by outsourcing some of the labor to partners; Fitzsimons \& Finkel, 2011; Fitzsimons et al., 2015). Alternatively, it may suggest that having more goals leads to the construction of a larger social network (perhaps having more goals leads people to seek others for assistance). Figure 1 depicts a typical goal system of a participant in this study.

\section{Hypothesis Tests}

Because partners were nested within participants, we used Linear Mixed modeling in SPSS to examine associations between the number of goals served by each partner and participants' relationship evaluations. We first ran models that included perceived network instrumentality (between-person, grand-mean-centered) and perceived partner instrumentality (within-person, person-mean-centered) as predictors of each relationship outcome. At the between-person level, there were significant positive effects of perceived network instrumentality on relationship closeness (parameter estimate $=.12(\mathrm{SE}=.04), t(282.43)=2.92$, $p=.004,95 \%$ confidence interval $(\mathrm{CI})=[.04, .20])$ conversation quality $($ parameter estimate $=$ $.08(\mathrm{SE}=.02), t(272.03)=3.15, p=.002,95 \% \mathrm{CI}=[.03, .12])$, and perceived social support $($ parameter estimate $=.07(\mathrm{SE}=.02), t(280.23)=3.19, p=.002,95 \% \mathrm{CI}=[.03, .11])$. Thus, people who perceive their overall networks as more instrumental to their goal pursuits tend to 
rate their relationships as closer, higher in conversation quality, and more supportive, on average, than do people who perceive their overall networks as less instrumental.

At the within-person level, there were also significant positive effects of person-meancentered perceived instrumentality interpersonal closeness (parameter estimate $=.62(\mathrm{SE}=.02)$, $t(195.24)=25.94, p<.001,95 \%$ confidence interval $(\mathrm{CI})=[.57, .66])$, conversation quality $($ parameter estimate $=.24(\mathrm{SE}=.01), t(148.86)=17.42, p<.001,95 \% \mathrm{CI}=[.22, .27])$, and perceived social support $($ parameter estimate $=.28(\mathrm{SE}=.01), t(200.43)=19.45, p<.001,95 \%$ $\mathrm{CI}=[.26, .31])$. These results support the hypothesis that number of goals served by a particular partner (relative to other partners in one's network) is positively associated with relationship evaluations with that partner.

In addition, the cross-level interaction emerged as significant for interpersonal closeness $($ parameter estimate $=-.08(\mathrm{SE}=.02), t(82.05)=-3.70, p=.0004,95 \% \mathrm{CI}=[.22, .27])$, and perceived social support (parameter estimate $=-.04(\mathrm{SE}=.01), t(104.51)=-3.13, p=.002,95 \%$ $\mathrm{CI}=[-.07,-.02])$, but not for conversation quality (parameter estimate $=-.02(\mathrm{SE}=.01), t(62.60)$ $=-1.30, p=.200,95 \% \mathrm{CI}=[-.04, .009])$. To probe the nature of the interactions on closeness and social support, we examined the simple effects of within-person perceived instrumentality at +1 SD and -1 SD of between-person perceived network instrumentality. For participants who perceived high network instrumentality (+ 1 SD), within-person perceived partner instrumentality was a significant positive predictor of perceived closeness $($ parameter estimate $=$ $.55(\mathrm{SE}=.03), t(75.90)=19.93, p<.001,95 \% \mathrm{CI}=[.49, .60])$ and perceived social support $($ parameter estimate $=.25(\mathrm{SE}=.02), t(96.59)=13.69, p<.001,95 \% \mathrm{CI}=[.21, .28])$. For participants who perceived low overall levels of network instrumentality (- 1 SD), within-person perceived partner instrumentality was also a significant positive predictor of perceived closeness 
$($ parameter estimate $=.70(\mathrm{SE}=.03), t(213.04)=20.28, p<.001,95 \% \mathrm{CI}=[.64, .77])$ and perceived social support $($ parameter estimate $=.33(\mathrm{SE}=.02), t(201.75)=15.62, p<.001,95 \%$ $\mathrm{CI}=[.29, .37])$. The parameter estimates and confidence intervals around them suggest that, although partner instrumentality is positively associated with relationship outcomes across levels of perceived network instrumentality, this within-person partner instrumentality effect is particularly strong among people who perceive lower levels of instrumentality across their networks.

We also examined the random slope and random intercept covariances for each model. This covariance was not significant for closeness, (parameter estimate $=-.02(\mathrm{SE}=.01)$, Wald Z $=-1.23, p=.218,95 \% \mathrm{CI}=[-.05, .01])$ but was significant for conversation quality (parameter estimate $=-.02(\mathrm{SE}=.005), \mathrm{Wald} \mathrm{Z}=-3.34, p=.001,95 \% \mathrm{CI}=[-.03,-.007])$ and perceived social support (parameter estimate $=-.02(\mathrm{SE}=.005), \mathrm{Wald} \mathrm{Z}=-4.24, p=.00002,95 \% \mathrm{CI}=[$ $-.03,-.01])$. The significant negative covariances indicate that the associations between partner instrumentality and these outcomes (conversation quality and social support) were stronger for participants who had lower mean levels of these outcomes (across their relationship partners) than they were for participants who had higher mean levels of these outcomes. Integrating these results with the cross-level interaction results reported above, our findings suggest that people who perceive lower levels of partner instrumentality, conversation quality, or social support across their networks are especially likely to tie their relationship evaluations to partner instrumentality.

Finally, we tested the multifinality constraints hypothesis (Köpetz et al., 2011) by examining the frequency of partners who serve increasing number of goals. These data are depicted in Figure 2. Partners who served zero (14\%) or one goal (24\%) were more common 
than partners who serve two goals $(30 \%)$. As the number of goals served increases to three (20\%), four ( $8 \%$ ), five (3\%), and six, (1\%), the percentage of partners who serves them continues to decline. These data suggest that partners who serve more goals are less abundant in social networks than partners who serve fewer goals, supporting the multifinality constraints hypothesis.

\section{Study 2: Partner Perceived Instrumentality Checklist}

Study 2 was designed as a replication of Study 1 with several important changes. While the self-generation of goals in Study 1 had the advantage of allowing participants to re-construct their own goal system, it had the disadvantage of relying on their ability to recall and communicate their goals. To address this limitation, participants in Study 2 were provided with a list of potential goals that partners may serve, and were asked to check the goals to which each partner was instrumental. The set of 10 goals provided was created using goals that participants self-generated in Study 1 (more details below).

Second, by having all participants report on the same set of goals, we were able to measure the importance of each goal to each participant, and to investigate whether weighting partner instrumentality (i.e., the number of goals served by each partner) by goal importance produced a meaningfully different index of partner instrumentality, that might be a stronger predictor of relationship evaluations than was our original (unweighted) instrumentality variable. This possibility was raised by Finkel and Eastwick (2015), who noted that partner instrumentality via multifinality may have a strong link to relationship evaluations "especially if those goals are high in chronicity and importance." Although it has been speculated that goal importance may influence the link between instrumentality and relationship evaluations, to date, this possibility has not been tested. Third, we included a measure of perceived responsiveness- 
the degree to which one perceives a partner as caring, understanding, and validating to oneself (Reis, Clark, \& Holmes, 2004) —in place of the conversation quality measure used in the first study. We expected that the number of goals a partner served would be positively associated with evaluations of that partner's responsiveness.

Finally, after analyzing the data from Study 1, and prior to analyzing the data from Studies 2 and 3, we pre-registered our hypotheses and data analytic plan for the test of the multifinality principle (osf.io/gbwmn), and continued to explore whether network instrumentality would moderate the association between partner instrumentality and evaluation.

\section{Participants}

Our recruitment target of 400 participants was determined to be the largest sample we could reasonably recruit in a single semester. In total, 398 participants started the study. Of these, 17 did not complete ratings for all of their social network members because the hour-long time for which they consented to participate had elapsed. Thus, complete data from 381 undergraduates (162 male, 218 female, 1 identified as non-binary) from an American university was used for data analyses. As in Study 1, because each participant was asked to report on multiple partners, we calculated the effective sample size at Level 1 (the level of the partner). Across the three relationship evaluation measures, the smallest effective sample size calculated was 1304. This sample size provided power of .95 to detect small-sized interaction effects $\left(\mathrm{f}^{2}=\right.$ .010), two-tailed, in analyses involving one predictor (in our case, partner instrumentality). The age of this sample ranged from $18-32$ years $(M=19, S D=1.4)$. Participants identified as White $(\mathrm{n}=270,70.9 \%)$, Asian $(\mathrm{n}=78,20.5 \%)$, Black $(\mathrm{n}=17,4.5 \%)$, Hispanic $(\mathrm{n}=5,1.3 \%)$ or another category $(\mathrm{n}=11,3 \%)$.

\section{Materials and Procedure}


Participants completed all study materials on a personal computer in a private room. Participants first completed individual difference measures not considered in the present investigation. Next, participants identified members of their social network by listing all the individuals with whom they had initiated contact in the past month. This was followed by the individual social network member evaluation in which participants indicated all of the goals for which each individual was instrumental (out of a set of 10 possibilities, and a box to enter an additional goal of their choosing, marked "other"). Participants continued the individual social network evaluation by completing measures of interpersonal closeness, perceived social support, and perceived responsiveness for each member.

Social Network Identification. Participants listed all the people with whom they had initiated contact in the past month, with allotted spaces for up to 30 people, following the recall procedure used by Dunbar and Spoors (1995) and Study 1.

Goal Importance. Participants were asked to "please rate the importance of each goal" on a scale ranging from not important at all (1) to extremely important (7). The goals (with mean importance scores indicated in parentheses) included academic goals $(M=6.47, S D=.75)$, career goals $(M=6.42, S D=.93)$, financial goals $(M=5.89, S D=1.15)$, health/fitness goals $(M$ $=5.50, S D=1.23)$, leisure/fun goals $(M=5.51, S D=1.12)$, personal improvement/growth goals $(M=5.98, S D=1.03)$, service/helping goals $(M=5.33, S D=1.36)$, sex/romance goals $(M=$ $4.90, S D=1.52)$, social support/social connection goals $(M=5.36, S D=1.29)$, and spiritual/religious goals $(M=3.62, S D=2.08)$. The goals were presented in the order listed here. Participants also had the opportunity to specify if they had another goal not covered by the above categories. Nineteen participants (5\%) listed an additional goal. We interpret the infrequent use of the other category as suggesting that our list is comprehensive. Indeed, most additions (e.g., 
friendship, getting good grades) could be captured by the checklist provided. To keep analyses the same across participants, we do not include the "other" category in the analyses reported.

Perceived Partner Instrumentality Checklist. As presented in Appendix A, participants were asked to complete a checklist for each of their social network members. Participants were asked to check a box for any goals for which their friend was instrumental out of the set of 10 goals provided (the same goals for which participants rated goal importance). Participants were provided with the same definition of instrumentality as in Study 1. The set of 10 goals was generated by the third author who entered all the goals into ORA from Study 1. This researcher, therefore, read and entered every goal from Study 1, then reviewed the entire set of goals to generate this list. The first author reviewed available goal checklists and sets of common motivations and generated a list of goals. The two lists were nearly identical, and any dissimilarities were resolved through conversation. Following this, two independent raters took a subsample of 30 participants from Study 1 and identified which of the goals on the checklists each generated goal would fit into. In no case did either rater fail to identify a goal category, nor did they have trouble identifying which category a goal would fit into. As a check on its comprehensiveness, we included the option of "other" for participants. In total, across all participants and targets, this option was used 55 times, which accounts for less than 1 percent of all participant $\times$ target ratings, suggesting that our list was indeed comprehensive.

Interpersonal Closeness. Participants were asked to complete the same interpersonal closeness items for each partner as in Study 1. In this sample, Cronbach's alpha ranged from .75 to .94 .

Perceived Social Support. Participants completed the same social support measure for each partner as in Study 1. In this sample, Cronbach's alpha ranged from .85 to .97. 
Perceived Responsiveness. We used a modified version of Reis's (2006) measure of perceived partner responsiveness, which included three additional items developed by Forest and Wood (2011) to capture the element of caring. Participants completed the scale for each partner. Sample items included, "This person understands me" and "This person really listens to me" $(1=$ not at all; $9=$ extremely). Cronbach's alpha ranged from .97 to .99 .

\section{Results and Discussion}

\section{Descriptive Statistics}

As can be seen in Table 2, participants reported an average social network size of about 16 partners and an average of 8.4 goals. Partners served an average of 3.4 goals each and each goal was served by an average of 5.3 partners. This resulted in a total of 6063 partners identified as means. About $75 \%$ of participants only listed instrumental partners, and about $25 \%$ listed at least one non-instrumental partner. In total, $95 \%$ of partners were instrumental to at least one goal. The number of goals identified was positively associated with active social network size $(r(279)=.38, p<.001)$. This replicates the association found in Study 1, and again suggests that having more partners may facilitate the pursuit of more goals and/or that having more goals may lead to the construction of a larger social network. The typical goal system for participants in this study is depicted in Figure 3.

\section{Hypothesis Tests}

Next, we investigated whether partners who served more goals were evaluated more positively, following the procedures outlined in our pre-registration (osf.io/gbwmn). In our preregistration, we described only examining person-mean-centered instrumentality (number of goals served) as a predictor of relationship outcomes. The analyses we report here (and Study 3) follow Bolger and Laurenceau's (2013) recommendation to include between-person predictors- 
in our case, (grand mean-centered) perceived network instrumentality as a predictor in analyses involving within-person effects. We also ran additional models (in this study and Study 3) that included a cross-level Partner Instrumentality $\times$ Network Instrumentality interaction term in order to explore whether effects of particular partners' instrumentality on relationship outcomes vary as a function of a participant's overall level of network instrumentality. Models using only the within-person partner instrumentality predictor, as described in our pre-registration revealed effects (here and in Study 3) of this predictor consistent in direction and significance with the within-person partner instrumentality results reported here.

Replicating Study 1, at the between-person level, there were significant positive effects of perceived network instrumentality on relationship closeness $($ parameter estimate $=.21(\mathrm{SE}=$ $.03), t(385.36)=8.00, p<.001,95 \% \mathrm{CI}=[.16, .26])$ and perceived social support (parameter estimate $=.14(\mathrm{SE}=.01), t(388.20)=9.28, p<.001,95 \% \mathrm{CI}=[.11, .17])$. There was also a significant positive effect of perceived network instrumentality on the new relationship outcome in Study 2, perceived partner responsiveness (parameter estimate $=.29(\mathrm{SE}=.04), t(396.42)=$ $7.95, p<.001,95 \% \mathrm{CI}=[.22, .36])$. These effects indicate that people who perceive their overall networks as more instrumental to their goal pursuits tend to rate their relationships as closer, and to perceive their partners as more supportive and responsive on average, than do people who perceive their overall networks as less instrumental.

Also replicating Study 1, at the within-person level, there were significant positive associations between (person-mean-centered) perceived partner instrumentality and interpersonal closeness $($ parameter estimate $=.50(\mathrm{SE}=.01), t(265.57)=42.13, p<.001,95 \%$ confidence interval $(\mathrm{CI})=[.47, .52])$ and between (person-mean-centered) perceived partner instrumentality and perceived social support (parameter estimate $=.27(\mathrm{SE}=.007), t(251.79)=37.46, p<.001$, 
$95 \% \mathrm{CI}=[.25, .28])$. There was also a significant positive association between (person-meancentered) perceived partner instrumentality and the new relationship evaluation measure, perceived partner responsiveness (parameter estimate $=.61(\mathrm{SE}=.02), t(269.97)=36.57, p<$ $.001,95 \% \mathrm{CI}=[.58, .65])$. These results support the hypothesis that the more goals a partner serves, relative to other partners in one's network, the more positively one evaluates the relationship with that partner (even when controlling for one's overall tendency to see partners as instrumental).

In addition, the cross-level interaction emerged as significant for interpersonal closeness $($ parameter estimate $=-.06(\mathrm{SE}=.008), t(301.61)=-7.95, p<.001,95 \% \mathrm{CI}=[-.08,-.05])$, perceived social support (parameter estimate $=-.04(\mathrm{SE}=.005), t(286.20)=-6.95, p<.001,95 \%$ $\mathrm{CI}=[-.05,-.03])$, and perceived partner responsiveness (parameter estimate $=-.07(\mathrm{SE}=.01)$, $t(303.02)=-6.07, p<.001,95 \% \mathrm{CI}=[-.10,-.05])$. To probe the nature of the interactions, we examined the simple effects of within-person perceived instrumentality at +1 SD and -1 SD of between-person perceived instrumentality. Analyses indicated that for participants who perceived high overall (mean) levels of partner instrumentality across their networks (+ 1 SD), within-person perceived partner instrumentality was a significant positive predictor of perceived closeness $($ parameter estimate $=.41(\mathrm{SE}=.02), t(246.71)=27.21, p<.001,95 \% \mathrm{CI}=[.38, .44])$, perceived social support $($ parameter estimate $=.22(\mathrm{SE}=.009), t(235.47)=23.67, p<.001,95 \%$ $\mathrm{CI}=[.20, .24])$, and perceived responsiveness $($ parameter estimate $=.52(\mathrm{SE}=.02), t(251.56)=$ $23.28, p<.001,95 \% \mathrm{CI}=[.47, .56])$, but that for participants who perceived low overall levels of partner instrumentality across their networks (- 1 SD), within-person perceived partner instrumentality was an even stronger positive predictor of perceived closeness (parameter estimate $=.60(\mathrm{SE}=.02), t(333.54)=34.86, p<.001,95 \% \mathrm{CI}=[.56, .63])$, perceived social 
support $($ parameter estimate $=.32(\mathrm{SE}=.01), t(315.01)=30.51, p<.001,95 \% \mathrm{CI}=[.30, .35])$, and perceived responsiveness (parameter estimate $=.73(\mathrm{SE}=.02), t(330.39)=29.17, p<.001$, $95 \% \mathrm{CI}=[.68, .78])$

We also examined the random slope and random intercept covariances for each model. This covariance was significant for all three relationship outcome measures: closeness $($ parameter estimate $=-.02(\mathrm{SE}=.008), \mathrm{Wald} Z=-3.12, p=.002,95 \% \mathrm{CI}=[-.04,-.009])$, perceived social support (parameter estimate $=-.01(\mathrm{SE}=.003)$, Wald $\mathrm{Z}=-4.84, p<.001,95 \%$ $\mathrm{CI}=[-.02,-.009])$, and perceived partner responsiveness (parameter estimate $=-.10(\mathrm{SE}=.02)$, Wald $\mathrm{Z}=-5.31, p<.001,95 \% \mathrm{CI}=[-.13,-.06])$. The significant covariances indicate that for participants who had lower mean levels of each particular relationship outcome (across their relationship partners), the association between partner instrumentality and relationship evaluations was stronger than it was for participants who had higher mean levels of that relationship outcome. Integrating these findings with the cross-level interaction findings reported above, our findings suggest that people who perceive lower (versus higher) levels of partner instrumentality, closeness, social support, or responsiveness across their networks are especially likely to tie their relationship evaluations to partner instrumentality.

Next, we examined whether weighting partner instrumentality by goal importance resulted in a meaningfully different instrumentality variable that might predict relationship evaluations more strongly than the unweighted instrumentality predictors we had used thus far. To create an index of weighted partner instrumentality for each partner, we multiplied each goal's importance (as rated by the participant) by the 0 or 1 rating of the partner's instrumentality to that goal $(0=$ partner is not instrumental to that goal; $1=$ partner is instrumental to that goal $)$ and summed these products across all 10 goals. We then person-mean-centered these weighted 
instrumentality scores to create a within-person weighted instrumentality variable. Examining raw correlations (not accounting for nesting within participants) between the unweighted and weighted instrumentality variable for each partner revealed that these indices of partner instrumentality were extremely highly correlated, $\mathrm{r}(6061)=.99, p<.001$. Thus, the weighted and unweighted instrumentality variables did not appear to be distinct. We consider these findings in the General Discussion.

Finally, we tested the multifinality constraints hypothesis (Köpetz et al., 2011) by examining the frequency of partners who serve increasing number of goals. These data are depicted in Figure 4. In this sample, partners who served zero goals were rare (5\%), but partners who served a single goal were most common (24\%), followed by two goals (19\%). As the number of goals increases to three (16\%), four (13\%), five (9\%), six, $(6 \%)$, seven (4\%), eight $(3 \%)$, nine $(2 \%)$, and ten $(1 \%)$, the percentage of partners who serve them continues to decline. As in Study 1, we interpret these data as suggesting that partners who serve more goals are less abundant in social networks than are people who serve fewer.

\section{Study 3: Perceived Partner Instrumentality Scale}

Our third study was designed to replicate the first two studies with a more sensitive measure of perceived partner instrumentality. Specifically, this study used a scale in which participants rated the extent to which participants were helpful or harmful to each of their goals. This allowed us both to determine how instrumental a person was to each goal (rather than simply checking yes or no as in the previous study) and allowed us to account for partners who may be detrimental to goal pursuit.

\section{Participants}

Our recruitment target of 400 participants was determined because it was the largest sample we expected that we could reasonably recruit in a single semester. In total, 396 
participants started the study. Of these, 11 did not complete ratings for all of their social network members. Thus, complete data from 385 undergraduates (134 male, 251 female) from an American university was used for data analyses. As in the prior studies, because each participant was asked to report on multiple partners, we calculated the effective sample size at Level 1 (the level of the partner). Across the three relationship evaluation measures, the smallest effective sample size calculated was 1161 . This sample size provided power of .95 to detect small effects $\left(\mathrm{f}^{2}=.011\right)$, two-tailed, in analyses involving one predictor (in our case, partner instrumentality). The age of this sample ranged from 18-28 years $(M=19, S D=1.2)$. Participants identified as White $(n=285,74 \%)$, Asian $(n=71,18.4 \%)$, Black $(n=17,4.4 \%)$, Hispanic $(n=3, .8 \%)$ or another category $(n=9,2.3 \%)$.

\section{Materials and Procedure}

Participants completed all materials on a computer in a private room. Participants first completed individual difference measures not considered in the present investigation. They then identified members of their social network by listing all of the individuals with whom they had initiated contact in the past month. Next, participants rated how instrumental each social network member was for each of nine goals. Finally, participants completed measures of interpersonal closeness, perceived social support, and perceived responsiveness for each network member as in Study 2 .

\section{Measures}

Social Network Identification. Participants were asked to list all of the people with whom they had initiated contact in the past month with allotted spaces for up to 30 people, following the recall procedure used by Dunbar and Spoors (1995) and Studies 1-2. 
Goal Importance. Participants were asked to "please rate the importance of each goal" on a scale ranging from not important at all(1) to extremely important(7). Participants were provided with 9 (of 10) of the goals included in Study 2. We re-worded "sexual/romantic goals" to "romantic or sexual relationship goals." Spiritual/Religious goals were dropped because the fewest number of participants endorsed those goals. The goals were presented in the following order: social support/social connection goals $(M=5.77, S D=1.24)$, romantic or sexual relationship goals $(M=5.08, S D=1.46)$, academic goals $(M=6.51, S D=.85)$, career goals $(M=$ $6.49, S D=.92)$, financial goals $(M=5.94, S D=1.14)$, health/fitness goals $(M=5.54, S D=$ 1.31), leisure/fun goals $(M=5.58, S D=1.10)$, personal improvement/growth goals $(M=5.94$, $S D=1.13)$, and service/helping goals $(M=5.24, S D=1.39)$. Participants also had the opportunity to specify if they had another goal not covered by the above categories. Thirty participants (7.8\%) listed an additional goal. As in Study 2, these additional goals were not included in subsequent analyses.

Perceived Partner Instrumentality Scale. As presented in Appendix B, participants were asked to rate how helpful or harmful each partner was to each goal on a scale ranging from extremely harmful(-5) to extremely helpful(+5). Instructions (adapted from Fitzsimons and Shah, 2008 and Studies 1-2) stated: "For your friend stated above, please indicate how much the person helps or harms your pursuit of this goal. A person is helpful to a goal if s/he makes it more likely that you will succeed. So, for example, a helpful person might be emotionally supportive or help you directly with that goal. A person is harmful to a goal if s/he makes it less likely that you will succeed. Note that being harmful for your goals doesn't mean that this person wants you to fail simply that he or she makes it less likely that you will succeed." We created a composite score 
by averaging across items (Cronbach's alpha's ranged from .81 to .95 across the 30 potential partners). The full set of instructions and items is presented in Appendix B.

Interpersonal Closeness. Participants were asked to complete the same interpersonal closeness items as in Studies 1 and 2 (Cronbach's alpha's ranged from .81 to .94 across the 30 potential partners).

Perceived Social Support. Participants completed the same measure as in Studies 1 and 2. (Cronbach's alpha's ranged from .86 to .97 across the 30 potential partners).

Perceived Responsiveness. Participants completed the same measure as in Study 2. (Cronbach's alpha's ranged from .97 to .99 across the 30 potential partners).

\section{Results and Discussion}

\section{Descriptive Statistics}

In this study, participants reported an average active social network size of about 17 people $(\mathrm{SD}=7.54)$. We first examined the average perceived instrumentality across all members of participants' social network. Perceived network instrumentality (across all partners listed for a participant) ranged from .04 to $4.91(M=1.62, S D=.83)$ on the -5 to +5 scale. This signifies that, in this sample, no participant had a social network that was harmful to goal pursuit overall. However, some participants had social networks that were close to zero. About $25 \%$ of social networks were below 1 on the -5 to +5 scale. Next we examined specific partners. A total of 6353 partners were listed. Of these, $242(3.8 \%)$ were harmful to goal pursuit (i.e., had total instrumentality scores below zero), and 507 (8\%) were neither helpful nor harmful to goal pursuit (i.e., had total instrumentality scores of zero). The remaining 5604 number (88.2\%) were helpful to goal pursuit (i.e., had mean instrumentality scores above zero).

\section{Hypothesis Tests}


Data analyses followed the procedures outlined in our pre-registration (osf.io/gbwmn) with the changes noted in Study 2. Replicating Study 2, at the between-person level, there were significant positive associations between perceived network instrumentality and relationship closeness $($ parameter estimate $=.65(\mathrm{SE}=.04), t(389.02)=15.52, p<.001,95 \% \mathrm{CI}=[.57, .74])$, perceived social support $($ parameter estimate $=.35(\mathrm{SE}=.02), t(393.75)=14.91, p<.001,95 \%$ $\mathrm{CI}=[.30, .40])$, and perceived partner responsiveness (parameter estimate $=.82(\mathrm{SE}=.06)$, $t(392.89)=14.19, p<.001,95 \% \mathrm{CI}=[.71, .94])$. These effects indicate that people who perceive their overall networks as more instrumental to their goal pursuits tend to rate their relationships as closer, and to perceive their partners as more supportive and responsive, on average, than do people who perceive their overall networks as less instrumental.

Also replicating Study 2, at the within-person level, there were significant positive associations between person-mean-centered perceived partner instrumentality and interpersonal closeness $($ parameter estimate $=.93(\mathrm{SE}=.02), t(297.99)=46.04, p<.001,95 \%$ confidence interval $(\mathrm{CI})=[.89, .97])$, between person-mean-centered perceived instrumentality and perceived social support (parameter estimate $=.52(\mathrm{SE}=.01), t(261.78)=42.53, p<.001,95 \%$ $\mathrm{CI}=[.50, .55])$, and between person-mean-centered perceived instrumentality and perceived partner responsiveness, $($ parameter estimate $=1.15(\mathrm{SE}=.03), t(280.09)=42.67, p<.001,95 \%$ $\mathrm{CI}=[1.10,1.20])$. These results support the hypothesis that the more instrumental a particular partner is to one's goals, relative to other partners in one's network, the more positively one evaluates that partner (even when controlling for the degree to which one sees partners as instrumental, on average).

The cross-level interaction emerged as significant for interpersonal closeness (parameter estimate $=-.15(\mathrm{SE}=.03), t(313.94)=-5.74, p<.001,95 \% \mathrm{CI}=[-.20,-.10])$, perceived social 
support $($ parameter estimate $=-.11(\mathrm{SE}=.01), t(302.08)=-7.71, p<.001,95 \% \mathrm{CI}=[-.14,-.08])$, and perceived partner responsiveness (parameter estimate $=-.21(\mathrm{SE}=.03), t(313.23)=-6.54, p$ $<.001,95 \% \mathrm{CI}=[-.28,-.15])$. To probe the nature of the interactions, we examined the simple effects of perceived partner instrumentality at +1 SD and -1 SD of perceived network instrumentality. Analyses indicated that for participants who perceived high overall (mean) levels of network instrumentality (+ 1 SD), perceived partner instrumentality was a significant positive predictor of perceived closeness (parameter estimate $=.81(\mathrm{SE}=.03), t(272.65)=28.89$, $p<.001,95 \% \mathrm{CI}=[.76, .87])$, perceived social support $($ parameter estimate $=.43(\mathrm{SE}=.02)$, $t(259.30)=27.08, p<.001,95 \% \mathrm{CI}=[.40, .46])$, and perceived responsiveness $($ parameter estimate $=.99(\mathrm{SE}=.04), t(270.29)=27.55, p<.001,95 \% \mathrm{CI}=[.92,1.06])$, but that for participants who perceived low overall levels of partner instrumentality across their networks ($1 \mathrm{SD})$, perceived partner instrumentality was an even stronger positive predictor of perceived closeness $($ parameter estimate $=1.06(\mathrm{SE}=.03), t(339.31)=34.44, p<.001,95 \% \mathrm{CI}=[1.00$, $1.12])$, perceived social support (parameter estimate $=.62(\mathrm{SE}=.02), t(330.94)=35.24, p<$ $.001,95 \% \mathrm{CI}=[.59, .66])$, and perceived responsiveness parameter estimate $=.1 .34(\mathrm{SE}=.04)$, $t(339.95)=34.28, p<.001,95 \% \mathrm{CI}=[1.26,1.42])$.

We also examined the random slope and random intercept covariances for each model. This covariance was not significant for closeness (parameter estimate $=-.02(\mathrm{SE}=.01)$, Wald Z $=-1.65, p=.10,95 \% \mathrm{CI}=[-.05, .004])$, but was significant and negative for perceived social support (parameter estimate $=-.01(\mathrm{SE}=.005)$, Wald $\mathrm{Z}=-3.04, p=.002,95 \% \mathrm{CI}=[-.02,-$ $.005])$, and perceived partner responsiveness (parameter estimate $=-.16(\mathrm{SE}=.03), \mathrm{Wald} \mathrm{Z}=$ $-5.86, p<.001,95 \% \mathrm{CI}=[-.22,-.11])$. The significant negative covariances indicate that for participants who had lower mean levels of social support and responsiveness, the association 
between partner instrumentality and relationship evaluations (social support or responsiveness) was stronger than it was for participants who had higher mean levels of that relationship outcome. In other words, people who perceive lower (versus higher) levels of social support or responsiveness across their networks are especially likely to tie their relationship evaluations to partner instrumentality.

Next, we examined whether weighting partner instrumentality by goal importance resulted in a predictor that was sufficiently different from the unweighted partner instrumentality variable. To create an index of weighted partner instrumentality for each partner, we multiplied each goal's importance (as rated by the participant) by partner's instrumentality for that goal on the -5 to +5 response scale and summed these products across all nine goals. We then personmean-centered these weighted instrumentality scores. The raw correlation between the unweighted and weighted instrumentality scores was $r(6062)=.99, p<.001$. As in Study 2 , we interpret these findings as suggesting that accounting for goal importance does not result in a substantially different variable. We return to this issue in the General Discussion.

\section{General Discussion}

The aims of the present research were to investigate whether (a) relationship partners who serve more goals are evaluated more positively than partners who serve fewer goals, and (b) relationship partners who serve more goals are less common in people's social networks than partners who serve fewer goals. The answers to these questions are important because they extend research on the link between partner instrumentality and interpersonal evaluation — which has reached consensus as a basic principle of close relationships and goal pursuit research — to cases in which partners serve multiple goals. While previous authors have speculated regarding the possibility that a multifinal partner may be evaluated more positively, the present research is the first empirical investigation of this possibility. The three studies reported here find consistent 
support for both the hypotheses that the number of goals a partners serves is positively associated with evaluations of that partner, and that such multifinal partners are less common in social networks than partners who serve fewer goals.

Our findings also revealed that participants who had lower quality relationships in general (less instrumental, supportive or responsive) exhibited a stronger link between partner instrumentality and evaluations of the partner. This could indicate that people who have less helpful social networks - who may therefore have greater need for instrumental partners - are more sensitive to partner instrumentality when evaluating their partners. Such sensitivity could be conducive to successful goal pursuit, insofar as it leads people to prioritize relationships with partners who are most instrumental. Alternatively, these findings could suggest that people who tie their evaluations of others closely to instrumentality develop less instrumental, responsive and supportive social networks. Future research could examine these possibilities.

In Studies 2 and 3, we considered the role of goal importance. Weighting partner instrumentality by importance of the goals served yielded variables that were extremely highly correlated with the unweighted partner instrumentality variables in those studies. Thus, considering goal importance when assessing instrumentality does not seem to yield a meaningfully distinct predictor from that obtained when goal importance is not considered. Why might this be? One possible explanation is that partner instrumentality to any goal is valued, and accounting for goal importance does not add explanatory power (in these studies, or in everyday life). This explanation is consistent with previous research suggesting that accounting for the importance of a self-esteem domain does not add explanatory power above general self-esteem (Marsh, 1986), and that weighting stressors by their importance does not seem to offer better prediction (e.g., Turner, \& Wheaton, 1995). Alternatively, participants may be inaccurate when 
self-reporting goal importance (e.g., academic pursuits were consistently rated as more important than social connection, which is unlikely given the fundamental nature of social connection needs), and/or goal importance may not be a stable enough variable to measure in this way (e.g., Fitzsimons \& Fishbach, 2010; Fishbach, Zhang, \& Koo, 2009; Kruglanski et al., 2002).

The studies reported here suggest that people experience intimacy and feel supported in relationships in which a partner is intimately embedded in their goal pursuits in such a way that they become a central means, serving many goals. It suggests that people will feel more distant from partners who become instrumental to fewer goals. Further, it suggests that if a person would like to draw interpersonally closer to someone else, s/he may want to become instrumental to more of that partner's goals and have that partner become instrumental to more of his or her own goals. Similarly, partners may protect their social bond by looking for ways to serve multiple goals across time, and flexibly adapting their instrumentality so that they are able to support their partners as they attain current goals and adopt new ones. Therefore, partner multifinality may make important contributions to relationship formation, maintenance, stability, and dissolution — a fruitful direction for future research to explore.

One observation from the descriptive statistics in this study is that participants have social networks that include non-instrumental others. In Study 1, 14\% of partners were not instrumental to any goal. This estimate was reduced to 5\% in Study 2 when participants were provided with a checklist of goals. In Study 3, 8\% of partners were non-instrumental overall, with almost another $4 \%$ being at least somewhat harmful to goal pursuit overall. We suspect that non-instrumental others are partners who either were instrumental in the past or are expected to be instrumental in the future. We expect that they are likely candidates to be pruned from one's social network over time if they do not become instrumental, or, remain in one's network only 
because of felt obligation.

One limitation of the present research is the correlational nature of the design. While this feature is necessary in order to investigate multiple partners and multiple goals at once (a serious strength), it eliminates our ability to understand the causal pathways through which the present effects emerge. While previous research has demonstrated that manipulations of partner instrumentality increase relationship evaluations (Converse \& Fishbach, 2012; Fitzsimons \& Fishbach, 2010; Fitzsimons \& Shah, 2008; Slotter \& Gardner, 2011), no research has investigated whether this causal path holds true in cases in which partners serve multiple goals. In addition, no research has investigated the potential reverse causal direction. It remains possible that generally viewing a partner as supportive and responsive may lead a person to perceive them as instrumental to various pursuits. More interestingly, a supportive and responsive partner may be called upon to facilitate goals as a person sets them, leading the person to become instrumental to a larger set of goals. Because a responsive partner is one who should have an interest in meeting one's needs and supporting one's goal pursuits (Fitzsimons et al., 2015; Reis et al., 2004), it seems plausible that people would try to enlist responsive partners to serve as means to many of their goals (Fitzsimons et al., 2015). This possibility could be fruitfully explored in future research.

The studies presented here also had a number of strengths. These studies measured participants' perceptions of all of their active social network members across all of their goals. These strengths necessitated some limitations (e.g., the correlational design), and complement existing experimental work that investigates how changes in a single partner's instrumentality influence evaluation of that partner. This approach, which involved large samples of participants reporting on instrumentality and relationship outcomes with multiple partners each, yielded 
strong statistical power and replicable findings while investigating actual social network members and actual goals participants were pursuing. Because we have included all of a person's goals and all of a person's active social network members, we have been able to investigate this association in a robust and comprehensive way. This approach also uniquely allows us to control for a person's general response biases (via person-mean centering the predictors), the average instrumentality of their social networks (via the between-subjects factor), and to test for the interaction between average network instrumentality and a particular partner's instrumentality.

One exciting avenue for future research is to investigate whether some people tie their evaluations of others more closely to perceived instrumentality than do other people. Two possibilities stand out to us as especially worthy of investigation. First, people who are sensitive to others' instrumentality when evaluating those others may be people who are effective selfregulators and who are socially skilled. This suggests that some people more successfully align their social lives and goal pursuit, and when they do may benefit from this arrangement. A second possibility is that people who attempt to coerce or exploit others may rely on perceived instrumentality when evaluating others. For example, Machiavellian personality may predict a stronger instrumentality-evaluation linkage. Future research could explore these possibilities, as well as additional potential moderators of these effects.

\section{Conclusion}

Our findings suggest that partners who serve more (versus fewer) goals are evaluated more positively, and that partners who serve more (versus fewer) goals are relatively rare within people's social networks. The reason people do not have more multifinal partners is because they are hard to find. The rarity of people who are multifinal is partially why multifinal others are appreciated so much. They are the people who a person marries, calls their best friend, and feels 
the closest. In addition, the associations between a partner's instrumentality and relationship evaluations are particularly strong among people who perceive their networks as less instrumental, supportive, and responsive overall. Previous research has revealed that when people complete a goal, their felt closeness and appreciate of a person who was recently instrumental decreases (Converse \& Fishbach, 2012; Fitzsimons \& Fishbach, 2010; Fitzsimons et al., 2010). The present research may suggest an important antidote to such fleeting interpersonal closeness: becoming a multifinal means with connections across a person's goals. 


\section{References}

Armstrong III, B. F., \& Kammrath, L. K. (2015). Depth and breadth tactics in support seeking. Social Psychological and Personality Science, 6(1), 39-46.

Aron, A., Aron, E. N., \& Smollan, D. (1992). Inclusion of Other in the Self Scale and the structure of interpersonal closeness. Journal of Personality and Social Psychology, 63, 596-612.

Bolger, N., \& Laurenceau, J. P. (2013). Intensive longitudinal methods: An introduction to diary and experience sampling research. New York: Guilford.

Carley, K. M., \& Reminga, J. (2004). ORA: Organization Risk Analyzer. Technical Report, Carnegie Mellon University, School of Computer Science, Institute for Software Research International, URL: http://www.casos.cs.cmu.edu/projects/ora/publication s.html

Chun, W. Y., Kruglanski, A. W., Sleeth-Keppler, D., \& Friedman, R. S. (2011). Multifinality in implicit choice. Journal of Personality and Social Psychology, 101, 1124-1137.

Converse, B. A., \& Fishbach, A. (2012). Instrumentality boosts appreciation: Helpers are more appreciated while they are useful. Psychological Science, 23, 560-566.

Dunbar, R. I., \& Spoors, M. (1995). Social networks, support cliques, and kinship. Human Nature, 6, 273-290.

Finkel, E. J., \& Eastwick, P. E. (2015). Interpersonal attraction: In search of a theoretical Rosetta stone. Handbook of personality and social psychology: Interpersonal relations and group processes. Washington, DC: American Psychological Association.

Finkel, E. J., Hui, C. M., Carswell, K. L., \& Larson, G. M. (2014). The suffocation of marriage: Climbing Mount Maslow without enough oxygen. Psychological Inquiry, 25, 1-41. 
Fishbach, A., Shah, J. Y., \& Kruglanski, A. W. (2004). Emotional transfer in goal systems. Journal of Experimental Social Psychology, 40(6), 723-738.

Fishbach, A., Steinmetz, J., \& Tu., Y. (2016). Motivation in a social context: Coordinating personal and shared goal pursuits with others. In A. Elliot (Ed.). Advances in Motivation Science, 3, 35-79.

Fishbach, A. \& Tu., Y. (2016). Pursuing goals with others. Social and Personality Psychology Compass, 1-15.

Fishbach, A. Zhang, Y., \& Koo, M. (2009). The Dynamics of Self-Regulation. European Review of Social Psychology, 20, 15-344.

Fitzsimons, G. M., \& Finkel, E. J. (2011). Outsourcing self-regulation. Psychological Science, 22, 369-375.

Fitzsimons, G. M., Finkel, E. J., \& Vandellen, M. R. (2015). Transactive goal dynamics. Psychological Review, 122, 648-673.

Fitzsimons, G. M., \& Fishbach, A. (2010). Shifting closeness: interpersonal effects of personal goal progress. Journal of Personality and Social Psychology, 98, 535-549.

Fitzsimons, G. M., \& Shah, J. (2008). How goal instrumentality shapes relationship evaluations. Journal of Personality and Social Psychology, 95, 319-337.

Forest, A. L., \& Wood, J. V. (2011). When partner caring leads to sharing: Partner responsiveness increases expressivity, but only for people with low self-esteem. Journal of Experimental Social Psychology, 47, 843-848.

Hoffman, L. (2014). Longitudinal analysis: Modeling within-person fluctuation and change. Taylor and Francis. http://www.pilesofvariance.com/

Köpetz, C., Faber, T., Fishbach, A., \& Kruglanski, A. W. (2011). The multifinality constraints 
effect: How goal multiplicity narrows the means set to a focal end. Journal of Personality and Social Psychology, 100, 810-826.

Kruglanski, A. W., Köpetz, C., Bélanger, J. J., Chun, W. Y., Orehek, E., \& Fishbach, A. (2013). Features of multifinality. Personality and Social Psychology Review, 17, 22-39.

Kruglanski, A. W., Shah, J., Fishbach, A., Friedman, R., Chun, W., \& Sleeth-Keppler, D. (2002). A theory of goal systems. Advances in Experimental Social Psychology (Vol. 34, pp. 331-378). San Diego, CA: Academic Press.

Lakey, B., Vander Molen, R., Fles, E., \& Andrews, J. (2016). Ordinary social interaction and the main effect between perceived support and affect. Journal of Personality, 84, 671-684.

Light, A. E., \& Fitzsimons, G. M. (2014). Contextualizing marriage as a means and a goal. Psychological Inquiry, 25, 88-94.

Marsh, H. W. (1986). Global self-esteem: Its relation to specific facets of self-concept and their importance. Journal of Personality and Social Psychology, 51(6), 1224-1236.

Neal, A., Ballard, T., \& Vancouver, J. B. (2017). Dynamic Self-Regulation and Multiple-Goal Pursuit. Annual Review of Organizational Psychology and Organizational Behavior, 4, 401-423.

Orehek, E. (2018). Close relationships and goal pursuit: A people as means perspective. In C. Kopetz \& A. Fishbach (Eds.) The Motivation-Cognition Interface: From the Lab to the Real World (pp. 131-151) New York: Routledge.

Orehek, E., \& Forest, A. L. (2016). When people serve as means to goals: Implications of a motivational account of close relationships. Current Directions in Psychological Science, $25,79-84$. 
Orehek, E., Forest, A. L., \& Barbaro, N. (in press). A people-as-means approach to interpersonal relationships. Perspectives on Psychological Science.

Orehek, E., Mauro, R., Kruglanski, A. W., \& van der Bles, A. M. (2012). Prioritizing association strength versus value: the influence of self-regulatory modes on means evaluation in single goal and multigoal contexts. Journal of Personality and Social Psychology, 102, $22-31$.

Orehek, E., \& Vazeou-Nieuwenhuis, A. (2013). Sequential and concurrent strategies of multiple goal pursuit. Review of General Psychology, 17, 339-349.

Orehek, E. \& Vazeou-Nieuwenhuis, A. (2016). On the obesity problem: Policy implications of a motivational account of (un)healthy eating. Social Issues and Policy Review, 10, 151180.

Orehek, E. \& Weaverling, C. G. (2017). On the nature of objectification: Implications of considering people as means to goals. Perspectives on Psychological Science.

Pierce, G. R., Sarason, I. G., \& Sarason, B. R. (1991). General and relationship-based perceptions of social support: are two constructs better than one?. Journal of Personality and Social Psychology, 61(6), 1028.

Reis, H. T. (2006). The perceived responsiveness scale. Unpublished manuscript, University of Rochester.

Reis, H. T., Clark, M. S., \& Holmes, J. G. (2004). Perceived partner responsiveness as an organizing construct in the study of intimacy and closeness. In D. J. Mashek \& A. P. Aron (Eds.), Handbook of closeness and intimacy (pp. 201-225). Mahwah, NJ: Erlbaum.

Slotter, E. B., \& Gardner, W. L. (2011). Can you help me become the "me" I want to be? The role of goal pursuit in friendship formation. Self and Identity, 10, 231-247. 
Turner, R. J., \& Wheaton, B. (1995). Checklist measurement of stressful life events. In S. Cohen, R. C. Kessler, \& L. Underwood Gordon (Eds.), Measuring stress: A guide for health and social scientists (pp. 29-58). New York, NY: Oxford University Press.

Vancouver, J. B., Weinhardt, J. M., \& Schmidt, A. M. (2010). A formal, computational theory of multiple-goal pursuit: integrating goal-choice and goal-striving processes. Journal of Applied Psychology, 95(6), 985-1008. 
Table 1. Descriptive Statistics (Study 1)

\begin{tabular}{lcc}
\hline Variable & M & SD \\
\hline Social Network Size & 8.77 & 3.67 \\
Total Number of Goals & 9.38 & 6.40 \\
Number of Goals per Partner & 2.00 & 1.40 \\
Number of Partners per Goal & 2.02 & 1.01
\end{tabular}


Table 2. Descriptive Statistics (Study 2)

\begin{tabular}{lcc}
\hline Variable & M & SD \\
\hline Social Network Size & 15.91 & 7.13 \\
Total Number of Goals & 8.42 & 1.76 \\
Number of Goals per Partner & 3.41 & 1.43 \\
Number of Partners per Goal & 5.26 & 3.12
\end{tabular}




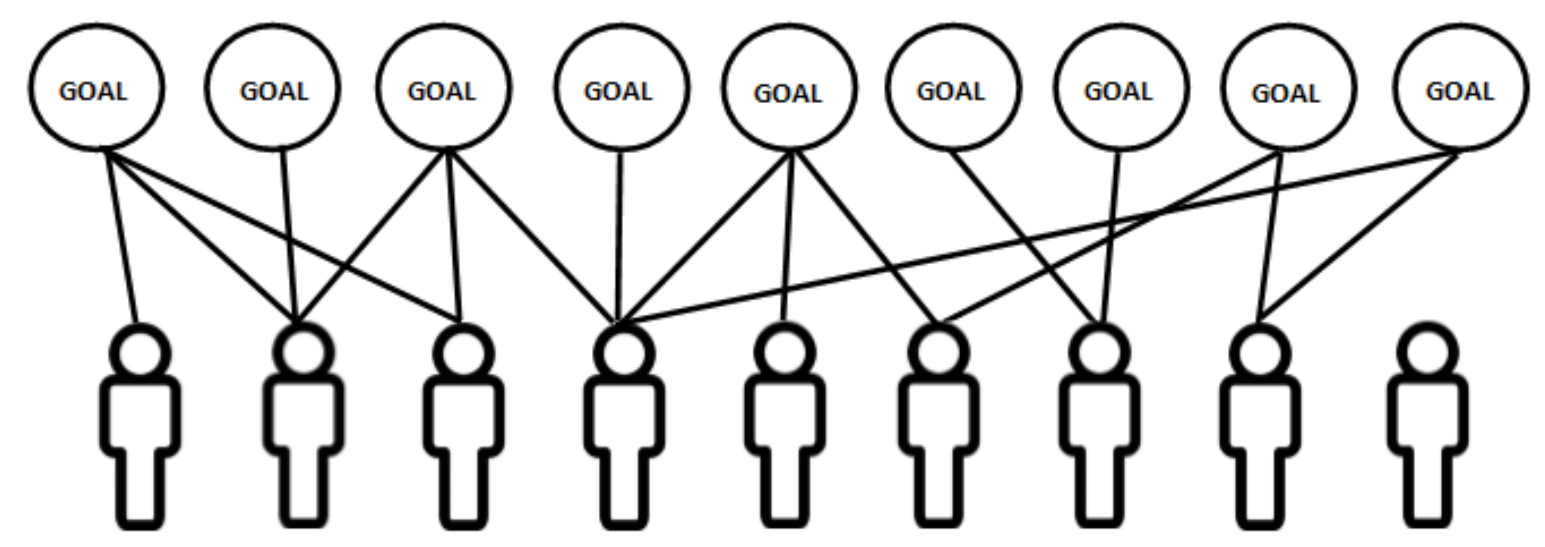

Figure 1. Visualization of a Typical Social Network Goal System in Study 1, with people serving as means to goals. 


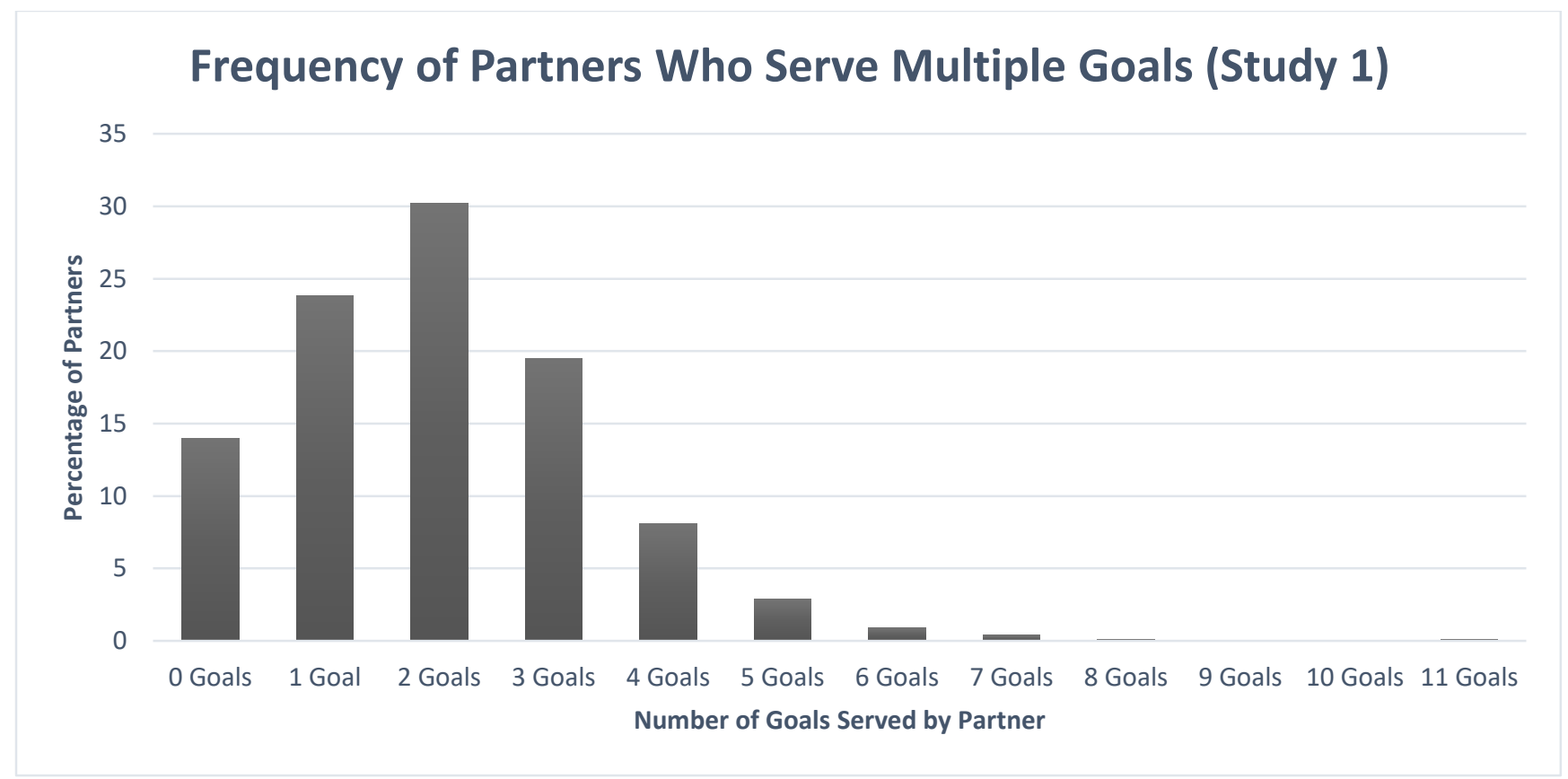

Figure 2. Frequency of Partners Who Serve Multiple Goals (Study 1) 


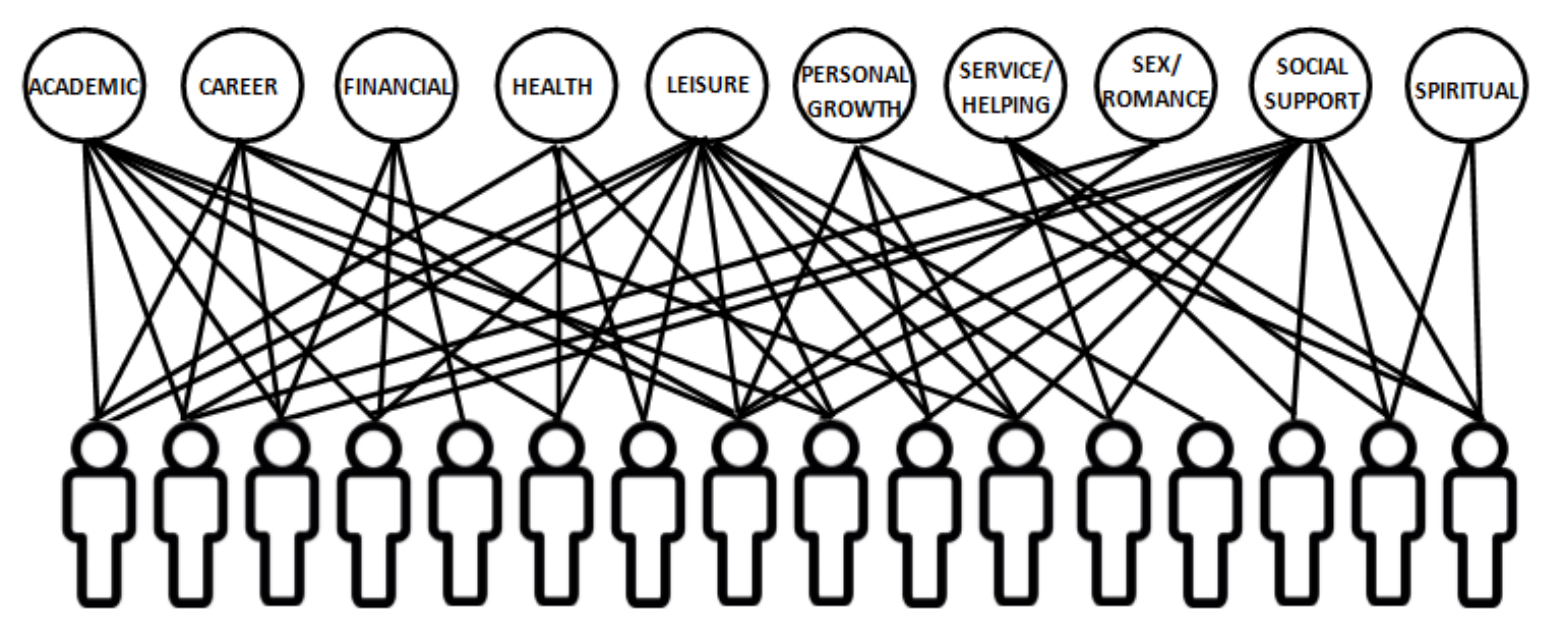

Figure 3. Visualization of a Typical Social Network Goal System in Study 2, with people serving as means to goals. 


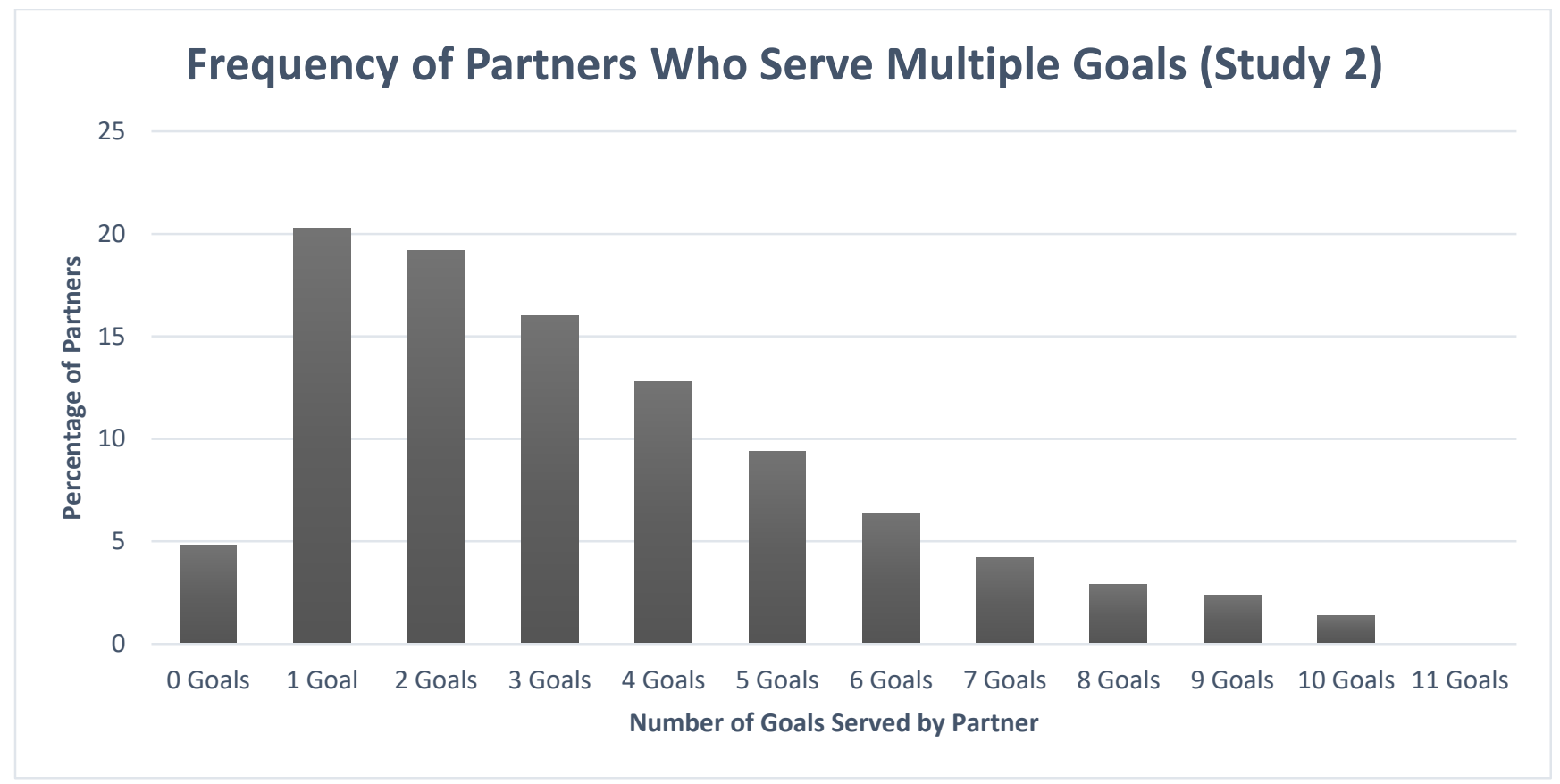

Figure 4. Frequency of Partners Who Serve Multiple Goals (Study 2) 


\section{Appendix A. Partner Perceived Instrumentality Checklist}

Instructions: Please answer the following questions about [INSERT NAME]

We are interested in how the people in your life affect your pursuit of your goals (i.e., goals to do well in general as well as specific goals, like getting a good grade on an upcoming exam, losing ten pounds, etc.). Please answer the following questions. It is a little tricky to understand, so please read carefully.

For your friend stated above, please indicate any goals for which they are instrumental. A person is instrumental to a goal if s/he makes it more likely that you will succeed. So, for example, an "instrumental person" might be emotionally supportive or help you directly with that goal. Note that being "non-instrumental" for your goals doesn't mean that this person wants you to fail simply that he or she doesn't make it more likely that you will succeed.

Please check each goal for which [INSERT NAME] is instrumental.
- Academic Goals
- Career Goals
- Financial Goals
○ Health/Fitness Goals
○ Leisure/Fun Goals
- Personal Improvement/Growth Goals
- Service/Helping Goals
- Sex/Romance Goals
- Social Support/Social Connection Goals
- Spiritual/Religious Goals 


\section{Appendix B. Partner Perceived Instrumentality Scale}

Instructions: Please answer the following questions about [INSERT NAME]

We are interested in how the people in your life affect your pursuit of your goals (i.e., goals to do well in general as well as specific goals, like getting a good grade on an upcoming exam, losing ten pounds, etc.). Please answer the following questions. It is a little tricky to understand, so please read carefully.

For your friend stated above, please indicate how much the person helps or harms your pursuit of this goal. A person is helpful to a goal if s/he makes it more likely that you will succeed. So, for example, a helpful person might be emotionally supportive or help you directly with that goal. A person is harmful to a goal if s/he makes it less likely that you will succeed. Note that being harmful for your goals doesn't mean that this person wants you to fail - simply that he or she makes it less likely that you will succeed.

Please indicate how much [INSERT NAME] helps or harms your pursuit of these goals.

1. Social Connection/Social Support Goals

2. Romantic or Sexual Relationship Goals

3. Academic Goals

4. Career Goals

5. Financial Goals

6. Health/Fitness Goals

7. Leisure/Fun Goals

8. Personal Improvement/Growth Goals

9. Service/Helping Others Goals

Scale: -5 (Extremely Harmful) to 0 (Neither Helpful nor Harmful) to 5 (Extremely Helpful). 